\title{
Sátira e alienação na construção do narrador não confiável em Goethe e Machado de Assis
}

Ana Laura dos Reis Corrêa ${ }^{1}$

\begin{abstract}
Resumo:
A partir da leitura de Os sofrimentos do jovem Werther, com base nos artigos de György Lukács e Miguel Vedda sobre esse romance de Goethe, e considerando o conjunto da obra de maturidade de Machado de Assis, quando o narrador assume a condução da narrativa guiando-a no ritmo frívolo e volúvel do capricho de classe, pretende-se investigar, neste texto, de que maneira a composição satírica de um narrador não confiável estabelece conexões entre esses dois escritores que deram forma sensível à alienação de uma "consciência infeliz".
\end{abstract}

Palavras-chave: sátira; alienação; narrador não confiável; Goethe; Machado de Assis.

\section{Satire and alienation in the construction of the unreliable narrator in Goethe and Machado de Assis}

\begin{abstract}
:
From the reading of The sufferings of young Werther, and based on the articles by Gyorgy Lukacs and Miguel Vedda about this novel by Goethe, as well as considering the whole of Machado de Assis' maturity work, when the narrator takes over the narrative and guides it in the frivolous and voluble rhythm of his class interests, this study seeks to investigate how the satirical composition of an unreliable narrator establishes connections between these two writers who have given an aesthetic form to the alienation of an "unhappy conscience".
\end{abstract}

Keywords: satire; alienation; unreliable narrator; Goethe; Machado de Assis.

No texto crítico Os sofrimentos do jovem Werther, escrito em 1936 sobre o romance de Goethe, György Lukács (2013), contrariando a recepção dominante desta obra pela historiografia burguesa, associa o sucesso internacional de Werther, em 1774, à momentânea hegemonia do Iluminismo

\footnotetext{
${ }^{1}$ Doutora em Literatura e professora do Programa de Pós-graduação em Literatura Brasileira da Universidade de Brasília (UnB). E-mail: analauradosreiscorrea@gmail.com.
} 
alemão em relação à persistente liderança de França e Inglaterra nesse terreno da arte e da filosofia. Lukács afirma que o provável espanto do leitor frente à associação entre Werther e o Iluminismo deriva de uma "lenda literária" que interpôs uma espécie de "muralha da China entre o Iluminismo e o classicismo alemão" (2013, p. 1).

Miguel Vedda (2015), em O jovem Goethe e a literatura sentimental: Os sofrimentos do jovem Werther como anatomia da consciência infeliz, também inicia sua análise desse romance do jovem Goethe sublinhando a atmosfera lendária que envolveu esta obra, que, ao "alcançar uma popularidade quase mítica" (2015, p. 61), foi sendo "saqueada" de sua complexidade para ser lida de forma cada vez mais simplificada e estereotipada. A dimensão lendária se condensou ainda mais pelas crescentes sugestões de aproximação entre ficção e realidade, entre a vida do personagem-narrador e a biografia do autor.

Dos pressupostos iniciais das duas análises de Werther, expostos sumariamente, pode-se inferir que o ambiente lendário em que a obra foi inserida cristalizou (VEDDA, 2015) o efeito crítico em uma espécie de defeito crítico, que ocultou dimensões essenciais do romance e o afastou de seu núcleo central e mais potente: a verdadeira tragédia não se restringe ao suicídio por amor ou por idealismo do espírito livre de artista em confronto com a sociedade mesquinha e pragmática, mas diz respeito, antes, à condição alienada do intelectual na modernidade. Tal alienação, expressa especialmente por um ressentimento intelectual, por uma "consciência infeliz", por uma nostalgia (lendária?) pela vida simples e natural, é descristalizada por Goethe, em Werther, por meio de alguns elementos formais, entre eles a composição satírica de um narrador não confiável.

No Brasil do século XIX, em condições diferentes das que circundam o cenário da literatura alemã do século XVIII, Machado de Assis (1839-1908), um escritor da periferia capitalista, em um momento de viravolta que produzirá um salto significativo em sua produção literária em direção a uma maturidade estética ainda inédita na literatura brasileira, também recorrerá à formulação satírica de um narrador nada confiável para a composição de romances e contos que alcançaram a complexidade da vida social brasileira em seu andamento frente ao contexto global do desenvolvimento capitalista.

Sobre a obra madura de Machado de Assis, após a publicação de Memórias póstumas de Brás Cubas, em 1881, também se formou uma nuvem de lendas literárias, cuja densidade não está ligada à aura mítica da popularidade de Werther, uma vez que a obra machadiana, evidentemente, jamais alcançou a universalidade do fenômeno goethiano. A realidade brasileira compartilhava, como a Alemanha, das dores do desenvolvimento das nações modernas, "sem compartilhar de seus prazeres, de suas satisfações parciais” (MARX, 2010, p. 153); mais ainda, na escala periférica e perversa da escravidão, o presente da vida social no Brasil se constituía como o passado 
mais remoto das nações modernas, e as possibilidades de haver no país alguma liderança no campo do pensamento abstrato era algo obviamente impossível. Nossa Alfklärung esteve ligada ao processo de independência, apoiado no discurso ilustrado, porém, o pensamento esclarecido esteve imensamente distante das lutas políticas reais pelo desenvolvimento e, restrito às apertadas fronteiras da incipiente elite local, transformou-se em "Perversão da Alfklärung”, como sintetiza Antonio Candido (2002): a fórmula ilustrada, reduzida a rótulo de prestígio de classe, não só inviabilizava qualquer possibilidade de horizonte de emancipação popular, quanto reafirmava, pelas mãos da classe dominante local, a permanência do estatuto colonial e escravocrata, em meio à importação de formulações ilustradas, e a dependência, em meio à jovem independência.

Em sua obra de maturidade, Machado dá forma artística a essa matéria social intensamente contraditória, mas o teor corrosivo de seus romances foi envolto por uma série de interpretações críticas que, em grande medida, atuaram no sentido de amenizar as contradições e brechas das estruturas sociais cristalizadas que seus romances puseram a mostra. Transformado em um escritor metafisico e diletante, interessado em filosofia, arte e religiões, ou em um cético e irônico comentador dos costumes urbanos, de costas para problemas sociais concretos, como a escravidão, Machado foi também muitas vezes confundido com seus mais importantes narradores em primeira pessoa. Brás Cubas, Bento Santiago, Conselheiro Aires, personagens que encarnavam precisamente, como nenhum outro até então, o modo de ser da débil burguesia local, foram encarados como portadores da visão de mundo de Machado; nada mais lendário, do ponto de vista literário e histórico, e nada mais difundido entre o senso comum. Tais desvios críticos do ponto fulcral da obra machadiana evitaram de todas as formas a exposição do caráter lendário da própria superfície da vida da classe dominante local, que, no dizer de Oswald de Andrade, tinha uma vida excelente, mas corrida em pista inexistente.

A obra de Machado começa a ser percebida em sua dinâmica efetiva, somente em 1960, quando a crítica feminista estadunidense Helen Caldwell (2002) faz ecoar em seu livro - O Otelo brasileiro de Machado de Assis: um estudo de Dom Casmurro - algumas poucas vozes que, na crítica contemporânea à Machado, já haviam manifestado alguma desconfiança quanto ao narrador Casmurro. A partir da relação com Shakespeare, que figura em D. Casmurro (1899) de maneira ostensiva na cena em que o narrador vai ao teatro assistir Otelo, Caldwell chama a atenção do leitor para o caráter parcial e suspeito de Bento Santiago, que imputa à sua esposa Capitu a culpa por seu destino infeliz, determinado pela simples desconfiança do narrador de que tivesse sido traído por ela e seu melhor amigo, Escobar. A culpa de Capitu é definida sem vacilação alguma por Bento, com base em apenas um olhar da mulher no momento do enterro de Escobar. A partir daí, o narrador passa a 
reconhecer imensa semelhança entre seu filho Ezequiel e o amigo morto, e, sem enfrentar a sua própria dúvida, decide sentenciar esposa e filho ao exílio na Europa, como forma de manter a violência de sua atitude peremptória sob os mantos das convenções sociais do sagrado matrimônio.

A razão do livro escrito por D. Casmurro é, segundo o narrador, "unir as duas pontas da vida", justificar sua melancolia, seu ensimesmamento em uma casa que é a réplica de sua casa da infância, o que acaba por demonstrar a sua incapacidade de agir, já anunciada pela inércia na infância e na juventude de Bentinho, sempre à sombra do caráter ativo da menina Capitu. Preso na cópia do passado - suas memórias -, como na cópia da casa materna, Bento Santiago narra sua transformação em Casmurro, escritor diletante, rico e solitário. A compaixão que reclama, apoiado nas convenções mais ocas e rígidas, o que lhe angariou retorno de muitos leitores adestrados nessas mesmas convenções cristalizadas, é o reflexo de seu mundo vazio e alienado. Como representante da classe dominante brasileira, Bento Santiago, que sempre viveu de renda, busca, pela escrita do livro, alcançar o seu verdadeiro objetivo: retorcer e violentar a realidade segundo a sua vontade minúscula e servil, porém impositiva e despótica: ser a cópia, sem contradição, de um projeto de vida, que, embora perdurante, não tem futuro vivo, uma condenação a ser casmurro que arrasta consigo, e violenta, tudo o que um dia poderia ter sido relação social viva e humana com Capitu, Escobar, Ezequiel. Essa dimensão local está articulada a uma causa mais profunda reproduzida pela primeira, como a réplica da casa original: a condição alienante da vida pequeno-burguesa, que se impõe como a única vida possível, ainda que seja uma vida casmurra. Bento Santiago é um personagem escritor, ele narra suas próprias memórias, mas é incapaz de reconstituí-las como representação viva das forças humanas; assim, a narrativa das memórias assume a aparência da natureza morta do fetiche: reprodução unilateral, estática e determinista de um quadro social sem vida, que esconde, "por trás das categorias reificadas (mercadoria, dinheiro, preço etc.) que determinam a vida cotidiana dos homens, a sua verdadeira essência, isto é, a de relações sociais entre os homens" (LUKÁCS, 2010, p. 19). Se for possível essa articulação entre a situação ficcional específica de D. Casmurro, em sua dimensão local, e o processo histórico mais geral e concreto de alienação, perceberemos que Bento Santiago é um narrador não confiável não apenas porque deforma de maneira interessada os fatos narrados, mas porque sua narrativa de memórias não pode efetivamente recordar o vivido, pois faz dele algo ainda mais perdido.

O leitor atento de Memórias póstumas de Brás Cubas, escrito quase duas décadas antes, contando com a evolução da crítica machadiana que foi pontuando o caráter não confiável do narrador, não pode deixar de reconhecer em $D$. Casmurro, por um lado, essa feição de cópia, uma visão de mundo que se impõe mesmo em desacordo com a realidade, com os acontecimentos e com 
a variedade que eles trazem consigo, mas, por outro lado, percebe que essa vida fantasmática reflete uma condição social e histórica concreta: a da alienação.

Memórias póstumas de Brás Cubas marca uma viravolta na obra de Machado, concentrada sobretudo na composição do narrador - cujo ponto de vista paternalista para com os de baixo, nos primeiros romances, passar a ser o de cima. Schwarz demonstrou que essa mudança do ponto de vista de classe não se resume "na troca da crítica (moderada) pela apologética, ou do ângulo dos oprimidos pelo dos opressores”, mas é parte "do novo dispositivo formal”, no qual

o narrador plantado no alto do sistema local de desigualdades (...) é uma consciência abrangente, que incita à leitura a contrapelo e à formação de uma superconsciência contrária [à do narrador] (SCHWARZ, 2004, p. 25).

Se considerarmos o caráter satírico que organiza essa estrutura, haveria alguma conexão possível entre o narrador não confiável de Memórias póstumas e o de Os sofrimentos do jovem Werther?

Não se trata de pensar essa conexão no sentido de uma influência imediata. Sabe-se que Machado conhecia a obra de Goethe. Não apenas Os sofrimentos do jovem Werther, mas também o Fausto e Os anos de aprendizado de Wilhelm Meister faziam parte da biblioteca de Machado, que, segundo Pimentel (1974), começou a estudar a língua alemã em 1883, aos 44 anos. As referências a Goethe, no entanto, estão presentes em poemas, contos e romances, anteriores e posteriores a 1883. São muitos os trabalhos de pesquisa em torno da influência fáustica na obra machadiana, especialmente quanto à dimensão luciferina do riso em Machado. A presença do diabo já aparece em 1863 no poema $\mathrm{O}$ casamento do diabo, cujo subtítulo sugestivo é Imitação do Alemão. O diabo também frequenta os contos machadianos, como o seu A igreja do diabo, de 1883, cujo segundo capítulo remete à cena "Prólogo no céu” da obra de Goethe. No romance Quincas Borba (1891), o capitalista Rubião tem em casa um par de estatuetas: Fausto e Mefistófeles. No conto O espelho, de 1882, o narrador apresenta a teoria das duas almas, uma interior e outra exterior, mas em Esaú e Jacó, de 1904, há uma referência direta a Goethe no capítulo "Duas almas", em que o narrador cita Goethe diretamente: "Ai, duas almas no meu seio moram!”.

Quanto ao Werther, o romance $A$ mão e a luva (1874) e o conto A mulher pálida (1881) apresentam protagonistas que correspondem ao estereótipo do jovem apaixonado, exagerado e depressivo. No romance, Estevão ama Guiomar, mas não é correspondido e acaba sendo rejeitado pela amada que se casa com o pragmático Luís Alves. Estevão, entretanto, apesar de pensar em morrer ou em fugir da cidade, acaba brasileiramente por evitar uma e outra saída, pois, diz o narrador, a "frouxidão do ânimo negou-lhe essa última ambição”. No conto, o personagem Máximo é uma espécie satírica de 
Werther brasileiro, que, rejeitado por sua amada, uma linda morena, que só lhe dará atenção quando Máximo ganha uma herança de um padrinho, nega o amor interessado da morena e o de qualquer outra mulher de carne osso, para sair à procura da mulher mais pálida do mundo, que, desafortunada e satiricamente, virá a seu encontro na figura da própria morte.

Sem desconsiderar essas e outras relações entre a obra de Machado e a de Goethe, nos interessa aqui pensar especialmente, embora brevemente, na conexão mais estrutural da forma de composição do narrador não confiável em Memórias póstumas e D. Casmurro e em Os sofrimentos do jovem Werther. Antes de chegar às conexões, é preciso considerar uma diferença importante entre os dois narradores. Werther é jovem, e, de acordo com Lukács (2013), exerce uma rebeldia que expressa "a insolúvel contradição entre o desenvolvimento da personalidade e a sociedade burguesa” (2013, p. 11). Bento Santiago é um homem melancólico e solitário, que rememora, cômoda e interessadamente, sua história, já ao final da vida. Brás Cubas, por sua vez, não é apenas um narrador velho, é bem mais que isso, é um defunto autor, tão à vontade e acomodado em sua vida pós-túmulo, quanto o foi na infância, juventude e velhice, jamais teve paixões extremas que ameaçassem sua paixão inabalável por si mesmo.

Apesar dessa diferença importante, que se relaciona a muitas outras que não poderemos abordar agora (pequena burguesia alemã e Brasil escravocrata, por exemplo), esses narradores velhos são volúveis e não confiáveis como o jovem Werther. Segundo Vedda (2015), o que caracteriza Werther como um narrador não confiável é, entre outras coisas, sua incapacidade de expressar artisticamente os fortes sentimentos e devaneios que lhe povoam o peito. Bento Santiago demonstra semelhante impossibilidade ao tentar compor um poema no capítulo "Um Soneto", em que ele escreve dois versos, mas não consegue de maneira alguma seguir adiante e conclui melancolicamente: “nada me consola daquele soneto que não fiz" (MACHADO DE ASSIS, 2015, p. 95). De acordo com Vedda (2015), a incapacidade de Werther está ligada a sua obsessão por cristalizar esteticamente a vida, promovendo uma relação tão imediata entre arte e vida que impedia o distanciamento necessário para a criação artística, assim, diz Vedda: "a contrapelo dos propósitos do autor, o público leu o Werther nos mesmos termos em que o protagonista do romance lia Homero ou Ossian: com aquela identificação desprovida de distância crítica que caracteriza o diletante" (VEDDA, 2015, p. 66, tradução minha).

As declarações de Werther a respeito da vida no campo, acomodada e simples, também não são dignas de confiança, uma vez que, salienta Vedda, "nada está mais distante dessa existência familiar singela e sedentária que o regime de vida de Werther, marcado sempre pela solidão e fuga" (VEDDA, 2015, p. 68). Os narradores machadianos em primeira pessoa dos romances da maturidade também são expressões de uma extrema incoerência entre o 
declarado e o feito: Brás Cubas "exibe o figurino de gentleman moderno, para desmerecê-lo em seguida, e voltar a adotá-lo, configurando uma inconsequência que o curso do romance vai normalizar" (SCHWARZ, 2000, p. 15).

Werther, conforme afirma Vedda, faz um uso totalmente pessoal das palavras de Cristo, mudando-lhes o sentido original em favor de sua percepção de mundo isolada, que, idealista, não faz caso das bases concretas sobre as quais se fundam os fatos. Werther consegue ver aproximação entre sua vida diletante e a de personagens simples, um criado, uma moça suicida e um escrevente louco, mas, em realidade, ao contrário de Werther, trata-se de "seres ingênuos, que, por causa de sua condição social ou mental, estão incapacitados de refletir sobre si mesmos” (cf. VEDDA, 2015, p. 79).

Em Machado, um dos momentos em que fica mais evidente o caráter volúvel do narrador é o conhecido episódio do Almocreve, em Memórias póstumas. Nesse capítulo, um simples almocreve, um condutor de bestas de carga, livra Brás Cubas de ser arrastado por um jumento no qual acabara de montar. Sabendo que o almocreve havia salvado sua vida ou evitado um desastre iminente, Brás Cubas pensa em recompensá-lo:

E era verdade; se o jumento corre por ali fora, contundia-me deveras, e não sei se a morte não estaria no fim do desastre; cabeça partida, uma congestão, qualquer transtorno cá dentro, lá se me ia a ciência em flor. O almocreve salvara-me talvez a vida; era positivo; eu sentia-o no sangue que me agitava o coração. Bom almocreve! enquanto eu tornava à consciência de mim mesmo, ele cuidava de consertar os arreios do jumento, com muito zelo e arte. Resolvi darlhe três moedas de ouro das cinco que trazia comigo; não porque tal fosse o preço da minha vida, - essa era inestimável; mas porque era uma recompensa digna da dedicação com que ele me salvou. Está dito, dou-lhe as três moedas. (MACHADO DE ASSIS, 1955, p. 103)

Ao retornar do susto imediato, porém, Brás Cubas volta a raciocinar a partir de seu lugar de classe - o de proprietário e rentista, alguém que, como ele mesmo afirma, nunca comprou o pão com o suor do seu próprio rosto”. Ao perceber a felicidade ingênua do almocreve ante a possibilidade da recompensa e ao examinar lhe a roupa e classificar o homem que salvou sua vida como "um pobre-diabo, que jamais vira uma moeda de ouro", o narrador muda totalmente de ideia e de atitude, baixa progressivamente o valor da recompensa - de três moedas de ouro para duas, depois uma, até chegar a um cruzado de prata. Recompensa que, segundo Brás Cubas, excedeu em muito o que o almocreve na verdade merecia - uns vinténs de cobre esquecidos no bolso de seu colete -, pois, afinal, reflete o narrador, o trabalhador não agiu pela recompensa ou pela virtude, mas apenas "cedeu a um impulso natural [de servir], cedeu aos hábitos do ofício"; ou foi um simples instrumento da Providência Divina, que também parece estar a serviço de Brás Cubas. $\mathrm{O}$ ato 
do almocreve é rapidamente aprisionado na moldura econômica caprichosa de Brás Cubas. A crescente desvalorização do ato do almocreve na cotação da consciência de classe do narrador - moeda de ouro, cruzado de prata e vintém de cobre - deseja anular o próprio almocreve, cujo mérito, como conclui Cubas, "era positivamente nenhum". No entanto, para o leitor capaz de tomar a distância crítica necessária do narrador, a composição da estrutura narrativa engendrada pelo autor deixa visível o avesso da situação narrada pelo próprio Brás Cubas: o decréscimo da estatura do narrador, que diminui na mesma proporção da oferta destinada ao almocreve, até chegar ao núcleo de sua perspectiva mesquinha e avarenta: "chamei-me pródigo, lancei o cruzado à conta das minhas dissipações antigas; tive (por que não direi tudo?) tive remorsos" (MACHADO DE ASSIS, 1955, p. 104). O valor das palavras "pródigo" e "remorsos" oscila entre generoso e gastador, entre arrependimento pelo mal feito ao outro ou em causa própria, reforçando o quanto esse narrador pouco confiável distorce os fatos segundo seus preconceitos de classe.

Diante desses elementos, a conexão entre esses narradores de Goethe e Machado, que aparece na estrutura dos textos, é, antes de tudo, a impossibilidade deles de perceber e interpretar os fatos para além de seus próprios limites. É sintomático que Werther encarnasse "o modo de sentir e pensar da juventude burguesa e pequeno-burguesa do período" (VEDDA, 2015, p. 61) e que Brás Cubas e Bento Santiago configurassem a posição de classe alienada da elite culta local.

A composição desses narradores como não confiáveis se conecta pelo fato de que seus criadores, Goethe e Machado, foram capazes de dar forma estética a essa consciência infeliz, seja pela sátira sutil da sensibilidade alemã (VEDDA, 2015, p. 62) que se refugia da alienação reinante numa nostalgia falaz; seja pela sátira aberta à desfaçatez da elite culta brasileira, cuja vida cristalizada busca de todas as formas violentar a realidade em nome de seus caprichos, mesmo que o saldo do seu inventário final seja o de uma infelicidade acomodada, como a de Bento Santiago que acaba seus dias como Casmurro, solitário, escrevendo memórias para atar duas pontas da vida que não se encontram, ou como a do defunto autor, Brás Cubas, que encerra sua narrativa vendo, como superávit, as negativas a que sua existência se resume - "Não tive filhos, não transmiti a nenhuma criatura o legado da nossa miséria" (MACHADO DE ASSIS, 1955, p. 158).

\section{Referências bibliográficas}

CANDIDO, Antonio. Perversão da Aufklärung. In: Textos de intervenção. Sel., apres. e notas Vinícius Dantas. São Paulo: Duas Cidades/Ed. 34, 2002, pp. 320-30.

CALDWELL, Helen. O Otelo brasileiro de Machado de Assis: um estudo de 
Dom Casmurro. São Paulo: Ateliê Editorial, 2002.

GOETHE, Johann W. von. Os sofrimentos do jovem Werther. Trad. e notas Marcelo Backes. Porto Alegre: L\&PM, 2012.

LUKÁCS, György. Os sofrimentos do jovem Werther. Trad. Patrícia Zimbres (2013), inédita. In: LUKÁCS, György. Goethe and His Age. Translator Robert Anchor. Londres: Merlin Press, 1968a.

- "Los sufrimientos del joven Werther". In: Goethe y su época Trad. castellana de Manuel Sacristán. Barcelona, México: Ediciones Grijalbo, 1968b. - Marx e o problema da decadência ideológica. In:

Marxismo e teoria da literatura. São Paulo: Expressão Popular, 2010, pp. 51103.

MACHADO DE ASSIS, Joaquim Maria. Memórias póstumas de Brás Cubas. São Paulo: W. M. Jackson, 1955.

D. Casmurro. São Paulo: Saraiva, 2015.

MARX, Karl. "Introdução". In: Crítica da filosofia do direito de Hegel Trad. Rubens Enderle e Leonardo de Deus. São Paulo: Boitempo. 2010.

PIMENTEL, A. Fonseca. A presença alemã na obra de Machado de Assis. Rio de Janeiro: Livraria São José, 1974.

SCHWARZ, Roberto. Um mestre na periferia do capitalismo. São Paulo: Ed. 34/Duas Cidades, 2000.

. A viravolta machadiana. Novos Estudos Cebrap, São Paulo, n. 69,

2004 .

VEDDA, Miguel. El Goethe temprano y la literatura sentimental. Los sufrimientos del joven Werther como anatomía de la conciencia infeliz. In: . Leer a Goethe. Ciudad Autónoma de Buenos Aires: Quadrata, 2015.

Como citar:

CORRÊA, Ana Laura dos Reis. Sátira e alienação na construção do narrador não confiável em Goethe e Machado de Assis. Verinotio - Revista on-line de Filosofia e Ciências Humanas, Rio das Ostras, v. 26, n. 1, pp. 194-202, jan./jun. 2020.

Data do envio: 15 mar. 2020

Data do aceite: 6 maio 2020 